\title{
Diáspora china en América Latina y su vinculación con la República Popular China
}

\section{Chinese Diaspora in Latin America and its relationship with the People's Republic of China}

DOI: $10.32870 /$ mycp.v10i29.708
Miguel A. Montoya ${ }^{1}$

\begin{abstract}
Resumen
El poder de la República Popular de China (RPC) despierta recelos sobre las poblaciones étnicas chinas, conocidas como "chinos de ultramar", al pensarse que prestan ayuda a la madre patria. En este estudio presentamos una visión de los chinos de ultramar en los países de América Latina en los que tienen mayor presencia; compartimos una descripción de sus comunidades y apuntes de su arribo a la región, y analizamos los temas distintivos en cada país. Realizamos un análisis buscando identificar el apoyo que la RPC recibe por parte de las comunidades chinas residentes en esa región. Para ello, comparamos dos muestras: en la primera se incluyen los países con una marcada presencia de los chinos de ultramar, mientras que en la segunda se agrupan los países que no tenían una comunidad numerosa de origen chino, pero que pudieran resultar atractivos para los planes chinos de expansión. Tras analizar los resultados presentamos nuestras conclusiones, donde se observa que el apoyo mutuo entre la RPC y los chinos de ultramar es débil, especialmente por parte de ese país.
\end{abstract}

Palabras clave: América Latina, China, chinos de ultramar, diáspora, geopolítica.

\begin{abstract}
The power of the People's Republic of China (PRC) arouses suspicions about the ethnic Chinese populations, known as "overseas Chinese" when they think that they are helping the mother country. In this study we present a vision of the overseas Chinese in the Latin American countries where they have the greatest presence; we share a description of their communities and notes of their arrival in the region, and we analyze the distinctive themes in each country. We conducted an analysis seeking to find the support that the PRC receives from the Chinese communities residing in that region. To do this, we compared two samples: the first includes countries with a strong presence of overseas Chinese, while the second group countries that did not have a large community of Chinese origin, but that could be attractive to Chinese expansion plans. After analyzing the results, we present our conclusions, where we found that mutual support between the PRC and the overseas Chinese is weak, especially in what concern to that country.
\end{abstract}

Keywords: Latin America, China, overseas Chinese, Diaspora, geopolitics.

Artículo recibido el 27 de junio de 2020 y dictaminado el 08 de febrero de 2021.

1. Tecnológico de Monterrey. Av. General Ramón Corona 2514 C. P. 45201, Zapopan, Jalisco. México. ORCID: https://orcid.org/0000-0002-5545-6334 Correo electrónico: mmontoya@tec.mx 


\section{Introducción}

En este artículo analizamos la diáspora de mayor impacto demográfico y comercial en la historia de la humanidad, aunque la circunscribimos al contexto latinoamericano. Buscamos sus raíces y analizamos sus principales elementos, pero eludimos los detalles históricos para privilegiar su impacto presente y previsible en el futuro inmediato. Nos referimos a la diáspora china, que lentamente ha desplazado muchos millones de personas desde el país asiático a gran parte del planeta. Lo ha hecho de manera llamativa moviendo a grandes grupos de personas y lo sigue haciendo de manera silenciosa, apoyándose en el auge económico de la República Popular de China (RPC). Precisamente la vinculación de las comunidades chinas en el exterior con su madre patria vuelve a esa relación un objeto importante de estudio desde la óptica geopolítica; es decir, desde el análisis de las interrelaciones entre la geografía, las poblaciones y su impacto en las decisiones de política y estrategia internacional de las naciones. Una visión más amplia de la geopolítica incorpora variables como la economía y la cultura, entre otras (Cuéllar, 2012), mismas que se conjugan en la nueva relación de China con el mundo.

La coyuntura geopolítica marcada por el ascenso de China en el escenario mundial y su creciente confrontación con el poder, hasta ahora hegemónico de Estados Unidos, abre grandes interrogantes sobre la posible neutralidad de comunidades de ciudadanos establecidos en un país, pero que mantienen vínculos ancestrales con la madre patria, posiblemente de subordinación. El tema no es de menor importancia, debido al apoyo que tales grupos puedan brindar a una de las partes en conflicto. Conviene recordar que las fricciones comerciales entre ambos países adquieren especial relevancia en el contexto de la expansión comercial de la RPC en el mundo, mediante el proyecto conocido como la Nueva Ruta de la Seda, OBOR o la Franja y la Ruta. Se trata de un proyecto de gran alcance, que comenzó en Eurasia, se extendió en África, y más recientemente lo hace en América Latina. La iniciativa de la Franja y la Ruta incluye la conexión de transporte intermodal entre más de 60 países, así como toda una red de infraestructura que facilitará la comunicación entre las naciones participantes, incluyendo la denominada nueva ruta digital, que permitirá la conectividad por redes de fibra óptica (Zottele \& Qian, 2017). Si bien las diásporas chinas no están consideradas directamente en el Proyecto de la Nueva Ruta de la Seda, sí que está el objetivo de vínculo de pueblo a pueblo "para promover los intercambios y diálogos entre diferentes culturas, 
fortalecer las interacciones amistosas entre los pueblos de varios países y aumentar el entendimiento mutuo y las amistades tradicionales. Todo esto constituirá la base para el avance de la cooperación regional" (The Hong Kong Trade Development Council [HKTDC Research], 2018).

Aunque el proyecto tiene una base de infraestructura logística y de intercambio comercial, las enormes aportaciones financieras por parte de empresas chinas y de instituciones bancarias de ese país le confieren también un papel en el escenario geopolítico. En última instancia, hay que considerar las ambiciones de la RPC de alcanzar el reconocimiento como superpotencia, aunque es también necesario entender que entre tales intereses no se incluye adquirir un papel hegemónico en el mundo, sino ser uno de los protagonistas en un mundo multipolar (Leverett \& Bingbing, 2017).

La palabra diáspora, de origen griego, evoca múltiples conceptos, entre ellos la migración de grandes grupos, generalmente perseguidos u obligados por diversos motivos, de un país de origen a varios países de recepción. En ese sentido, una diáspora es un caso extremo de migración de poblaciones o grupos extensos de personas, generalmente por eventos determinados en el tiempo, o por situaciones que se extienden por largos periodos de tiempo. Por ende, la diáspora posee la característica principal que diferencia a la migración internacional, es decir, el cambio de residencia a otro país, ubicándose en la categoría de migrantes de largo plazo (quienes se trasladan por más de un año), frente al otro gran grupo de migrantes de corto plazo (Organización Internacional para las Migraciones [OIM], 2020). Reúne los elementos que pudieran considerarse como esenciales para entender las causas de la migración, como son "las desigualdades socioeconómicas, las dinámicas demográficas y la gobernanza son los factores impulsores de la migración" (Canales, Fuentes \& De León, 2019).

Son elementos importantes de una diáspora: la inserción de un grupo con suficiente cohesión en el país que lo recibe, los llamativos signos externos que representan a esa comunidad, su establecimiento en un territorio que no es el de su origen, las relaciones que la unen con su lugar de origen y su amplia dispersión geográfica. En general, las connotaciones de una diáspora son de dolor y sacrificio de quienes abandonan su tierra, y de reinserción en lugares que a menudo son hostiles. La etimología de la palabra diáspora se relaciona con el alejamiento de un grupo completo desde su origen, como es el caso evidente del pueblo judío, una vez expulsado de territorios en los que se habían asentado históricamente (Ben-Rafael, 2013). Una segunda acepción, 
sin embargo, relaciona la diáspora con la salida de numerosos miembros de un grupo de su país, sea por coerción o búsqueda de oportunidades, aunque se requiere un evento de impacto dramático que merme su población en la tierra natal y la distribuya en múltiples territorios. Así, por ejemplo, no se puede hablar de diáspora en Irlanda, pese a que en el siglo XIx la hambruna empujara a muchos de sus habitantes a Norteamérica. Tampoco se puede hablar de diáspora italiana a las migraciones de sus nacionales a Sudamérica a principios del siglo Xx (Grillo, 2013). Sin embargo, entendemos que puede hablarse de diáspora china, ya que diferentes episodios como grandes persecuciones, el comercio humano denominado de los "coolies" o el desmembramiento de su patria, forzaron a millones a establecerse en diferentes rincones del planeta, llegando hoy en día a sumar probablemente más de 50 millones de personas (Portes \& Armony, 2016).

La diáspora china es universal, puesto que alcanza a unos 150 países, $\mathrm{y}$ ha generado el término de chinos de ultramar, que, si bien no está exento de polémica, describe a quienes residen fuera de la China continental, Hong Kong, Taiwán y Macao (Martínez \& Dussel, 2016). La denominación de chinos de ultramar pudiera definirse como aquellos que,
(...) aunque residen en cualquier parte del mundo, tienen una ascendencia patrilineal reconocida por el grupo que puede demostrar su vinculación espacial con el territorio hoy reconocido como China, entre los cuales existen marcadas diferencias lingüísticas, religiosas, de clase, de asimilación y de aculturación al lugar donde viven. (Cornejo, 1995)

Además de los factores mencionados, muchos otros agregan complejidad al tema de la identidad china. Al igual que se hace en este texto, es de uso común referirse a la madre patria como ese lugar ideal al que pertenece toda la población de origen chino, aunque probablemente sea más apropiado el término "tierra ancestral". El concepto de madre patria es más reciente y está vinculado a intereses geopolíticos de la RPC (Ford, 2015).

La presencia de los chinos de ultramar es relevante por su número, el poder económico, la singularidad de sus elementos distintivos y probablemente debido a la interpretación que muchas veces inspiran de ser comunidades externas que viven al margen de los países que las hospedan. En ciertos momentos esta diáspora ha tenido gran protagonismo al afectar al transnacionalismo de grupos importantes en temas de ciudadanía, derechos políticos y represen- 
tatividad. El transnacionalismo, que incluye todos los factores que conectan a una persona, su país de origen y el de residencia, adquiere una mayor dimensión en el caso de la población china, debido a la distancia cultural tan evidente que encuentra al asentarse en América Latina. El tema sigue sin ser enteramente resuelto, con episodios de discriminación en algunas naciones.

Las grandes migraciones chinas se han dado en un momento tardío de su larga historia debido al escaso interés de dejar la tierra de origen, a la que consideraban más importante que cualquier otra. Los primeros desplazamientos significativos probablemente empezaron con la dinastía Ming, en el siglo XIV, en un intento de asegurar la presencia comercial en territorios vecinos (Mote $\&$ Twitchett, 1988). Tras el ocaso de la dinastía, los invasores de Manchuria empujaron a los vencidos a escapar a Taiwán y Japón, lo que ocasionó la prohibición de abandonar el territorio chino por parte del nuevo emperador (Atwell, 1986). Posteriormente se sucedieron distintas olas migratorias, generalmente asociadas a conflictos políticos internos y a periodos de penuria económica o desintegración social. Tales situaciones llegaron a un punto de deterioro extremo tras las denominadas Guerras del Opio, hacia la mitad del siglo XIX, y la presencia de las potencias occidentales en China. Estas naciones obtuvieron privilegios comerciales importantes y desarrollaron el comercio de trabajadores bajo contrato, que en realidad escondía legalmente condiciones de semiesclavitud. Los trabajadores chinos, mediante promesas, engaños o por la fuerza, fueron llevados a países donde se necesitaban trabajadores que pudieran adaptarse a condiciones extremas, sea climatológicas, de hacinamiento, o por la exigencia de los trabajos a realizar.

La resistencia proverbial de los habitantes del sur de China y el deterioro de sus condiciones de vida favorecieron ese tipo de comercio humano. Posteriormente hubo dos momentos históricos de suma importancia para aumentar la diáspora, como son la invasión japonesa de la región de Manchuria perteneciente a China y grandes áreas de ese país, entre 1931 y 1945, y la guerra civil. En el primer caso, la dominación por parte de Japón y la brutalidad en el trato a la población local forzó a muchos habitantes a la emigración. En el segundo caso, tras la proclamación de la República Popular China en 1949, se produjo una gran migración interna hacia Taiwán y otra externa hacia otros países (Vázquez, 2006). Los periodos históricos mencionados fueron especialmente convulsos, debido a la guerra civil y la separación de la población entre los seguidores de Mao Tse-Tung y los de Chiang Kai Shek. La disputa finalizó con la huida del segundo a Taiwán y el establecimiento de la 
República Popular China, en 1947. La población de ultramar se dividió en su apoyo a ambos bandos, lo que incluso había ya ocurrido durante la ocupación japonesa (Kim, 2018).

A partir de ese momento, las nuevas migraciones disminuyeron su intensidad, tal vez con excepción de la producida tras la restitución de Hong Kong por parte del Reino Unido, en 1997, y la asociada al creciente poder económico de China, que desplaza a numerosos emigrantes junto a su comercio e inversiones (Li, 2005). Por lo tanto, puede decirse que la diáspora china en América Latina es un fenómeno ocurrido, en gran medida, con anterioridad al establecimiento de la RPC. Entre los factores de mayor impacto para la región latinoamericana pueden incluirse la necesidad de mano de obra tras la abolición de la esclavitud en el siglo XIX, los frecuentes conflictos sociales y las rebeliones que ensangrentaron a China, como en la rebelión Taiping, de la segunda década de ese siglo, resultando en 20 millones de muertos y la extensión de la pobreza (Fleischer, 2012). La historia de las diásporas chinas en Latinoamérica es muy amplia y el actual trabajo no pretende, ni podría, revisarlas en su totalidad. Ni trata de agotar su descripción, es un fenómeno amplio que no es cubierto en la totalidad en el presente.

Nuestra investigación aborda los temas mencionados, pero lo hace con un enfoque en América Latina. Tras la introducción, presentamos una visión sucinta de cómo se ha desarrollado la diáspora china, apuntando a determinados momentos en el tiempo y a un contexto que nos ayude a entender este fenómeno. Seguidamente presentamos un panorama general de la presencia de grupos de origen étnico chino en la región, seleccionando a varios países donde esas comunidades tienen un mayor peso específico. Este último cambia notablemente, por lo que en la sección subsiguiente nos avocamos a identificar los elementos que hacen singular a cada comunidad. Finalmente, analizamos la vinculación de los diferentes grupos con la madre patria con objeto de responder la gran interrogante: ¿sirven las poblaciones de origen chino establecidas en América Latina a los intereses de la RPC y, por ende, al expansionismo de ese país en la región? La respuesta a esa pregunta se presenta en la sección de los comentarios finales.

\section{Las comunidades chinas en América Latina}

La diáspora china también llegó a América Latina, aunque de manera menos evidente y en gran medida debido a la búsqueda de oportunidades de vida 
en la región y para trabajar en determinados proyectos, como por ejemplo la construcción de ferrocarriles, el reemplazo de los esclavos africanos tras la abolición de la esclavitud y donde se necesitaba mano de obra sumisa y resistente a las adversidades (Eng, 2013).

Debido a una serie de factores, es una tarea casi imposible la de encontrar las cifras de población de origen étnico chino residente en América Latina. El principal es que se carece de censos confiables en muchos países de la región, a lo que pueden agregarse algunos otros como la falta de autoidentificación de los chinos de ultramar como tales, la situación entendida como transitoria por parte de muchos de ellos, o la permanencia legal en cada país. La divergencia de datos presentados en distintas fuentes es tan importante que resulta difícil aceptarlos como válidos, de manera que señalamos la población estimada de cada comunidad de manera ilustrativa. A continuación presentamos una perspectiva general sobre las comunidades chinas en los países en los que tienen mayor presencia, siendo estos: Perú, Venezuela, Brasil, Panamá, Argentina, Cuba y México.

\subsection{Perú}

El país andino destaca claramente sobre las demás naciones, ya que tiene una comunidad arraigada, con peso económico y representación política. En los demás países ese poder se diluye en diferente medida, hasta llegar a los casos de Cuba y México. Estos últimos son casos opuestos, ya que en la isla caribeña es difícil que la comunidad china florezca, mientras que es previsible que lo haga de manera importante en el país norteamericano. Presentamos los diferentes casos en manera decreciente, conforme a una interpretación actual, misma que probablemente vaya cambiando en un futuro cercano debido al impacto de las inversiones de China y nuevas tendencias en la inmigración desde ese país.

La comunidad china en Perú es la mayor en población y poder en la región y es en parte el reflejo de uno de los patrones migratorios más antiguos entre el continente asiático y el americano. Además, la población local de ese origen étnico se involucra en brindar apoyo social, cultural y económico a sus compatriotas (Rodríguez, 2000). La comunidad tiene una organización encomiable, con influencia en diferentes aspectos de la sociedad local. Además de los lazos ancestrales con los núcleos geográficos origen de su emigración, tiene vínculos con comunidades en California, en ambos casos con acceso 
a recursos financieros que han respaldado las actividades comerciales en el barrio chino de Lima. Además, ha conservado sus valores ancestrales, en gran medida porque las familias y las asociaciones han sido fundamentales para mantener unidos a sus miembros, tanto internamente en el país anfitrión como externamente con la madre patria (Tamagno \& Velásquez, 2016).

\subsection{Venezuela}

El país sudamericano alberga la segunda comunidad étnica china más numerosa en América Latina, probablemente con cerca de 400,000 personas (Martín, 2017). Para muchos de ellos la llegada es reciente, aunque hay cuatro periodos migratorios distintos. La primera ola comenzó a mediados del siglo XIX, la segunda unos cien años después, la tercera durante los años setenta y la última todavía está en curso (Hearn, 2016). Los movimientos más recientes siguen al fortalecimiento de las relaciones bilaterales entre Venezuela y la República Popular China, debido a la proximidad ideológica entre sus líderes y la explotación a gran escala de depósitos de petróleo y minerales. Los factores políticos también estuvieron en la raíz de la tercera ola migratoria que ocurrió durante los años setenta, cuando algunos grupos vinieron de otros países. Muchos de los emigrantes llegaron desde la provincia de Guangdong, mientras que la ciudad de Valencia es el hogar de la comunidad más importante. De hecho, Valencia es famosa por sus festivales y mercados típicos, con muchos elementos de identidad cultural china (Lares, 2007). Como sucede en otros países, muchas personas de este grupo tienen un estatus ilegal en el país, pero su presencia es notable y últimamente han sido objeto de hostilidad y violencia.

\subsection{Brasil}

La inmigración china en Brasil se remonta al periodo colonial portugués, cuando los gobernantes locales los trajeron como esclavos de la antigua colonia de Macao y de Lisboa. Su conocimiento de la lengua portuguesa les permitió integrarse más fácilmente en la nueva sociedad (Conrad, 1975) y posteriormente muchos más chinos vinieron de Hong Kong, Guangdong y Macao. Lo hicieron en diferentes periodos históricos, principalmente tras la proclamación de la RPC en 1949 y tras el restablecimiento de relaciones bilaterales en 1974. Para entonces, la comunidad había alcanzado tanto el 
poder económico como el político, lo que finalmente permitió ofrecer un apoyo considerable a los recién llegados (Mei, 2014). Se calcula que puede haber más de 250,000 chinos étnicos en Brasil, formando una comunidad muy arraigada. Al menos 200,000 de ellos viven en el estado de Sao Paulo, en la mayoría de los casos con un estatus ilegal en el país y en muchos casos conviviendo junto a la próspera colonia japonesa (Bedinelli \& Veleda, 2010). La presencia de los brasileños originarios de China se vuelve paulatinamente más notable en el comercio y su capacidad de adaptación al nuevo entorno está favoreciendo la expansión a otras ciudades de Brasil, aunque en detrimento de su cultura ancestral.

\subsection{Panamá}

Los chinos llegaron al país del istmo desde América del Norte en la segunda mitad del siglo XIX. Al principio fueron contratados para trabajar en la construcción del ferrocarril nacional, pero pronto pudieron prosperar en el sector comercial. La prosperidad no llegó sin dolor, ya que sufrieron una constante discriminación y trabajaron en condiciones extremas en la selva, donde murieron por centenares. En muchos casos se suicidaron después de ser privados de opio, la droga que demandaban como medio de pago (Tam, 2006). En 1941 el gobierno local inició una persecución contra la población de origen chino, lo que provocó la creación de 35 asociaciones en todo el país (Hua, 2002). Otra ola significativa se produjo por razones políticas, con los que huyeron de su país después de los enfrentamientos en la Plaza Tiananmen (Johnston, 1990). Aunque no existen datos fidedignos, puede estimarse que hoy en día superan los 135,000 miembros en el país centroamericano. La comunidad chino-panameña ha podido conservar muchas de las tradiciones vernáculas. Sus ciudadanos han mantenido vínculos estables a través de la familia y las relaciones de mutuo apoyo, sea en un orden formal o mediante la práctica del Guanxi, donde las relaciones personales favorecen los intereses comerciales.

\subsection{Argentina}

La comunidad china en Argentina está formada por casi 120,000 miembros y es una de las más jóvenes de la región (Sánchez, 2010). Los momentos de situación económica estable sirvieron para atraer a muchos inmigrantes desde la provincia de Fujian. Se aventuraron en actividades minoristas y pronto 
lograron una posición dominante en los supermercados de la capital Buenos Aires. Tuvieron tanto éxito en este comercio como para desplazar a los recién llegados a otros lugares (Marrero, 2016). Esta comunidad mantiene poca cohesión, existiendo disputas internas, posiblemente debido a lo heterogéneo de la procedencia de sus miembros, tanto geográficamente como en el tiempo. Hay flujos de inmigración más reciente y con diferentes perfiles, incluyendo quienes vienen a estudiar, llegan con empresas chinas o desde otros países (Grimson et al., 2016).

\subsection{Cuba}

Se calcula que hay más de 100,000 cubanos de origen chino viviendo en la isla, por lo que constituyen la comunidad más importante en el Caribe. Su llegada no es reciente y han continuado arribando en diferentes momentos y por varias razones. La abrumadora mayoría fue traída por los españoles durante la época colonial, en condiciones de semiesclavitud, pero un grupo importante llegó a Cuba evadiendo la hostilidad encontrada a veces en Estados Unidos (Kenley, 2013). Esta comunidad es completamente diferente de las otras, ya que sus miembros pasaron por un proceso continuo de mezcla racial. La razón detrás de la adaptación distinta es porque los chinos que llegaron a la isla eran casi exclusivamente hombres y se casaron con mujeres criollas o mestizas (Hearn, 2016). La mayoría de los cubanos de origen chino también tienen ascendencia africana y española (Vidal, 2003). A pesar de su profunda adaptación a la sociedad local, los chinos de ultramar en Cuba han podido mantener su identidad cultural (Jiménez, 1983). Este grupo tuvo una participación importante en la política, más allá de la defensa de sus intereses comerciales o la defensa de sus derechos fundamentales, y ha tenido una aportación significativa en el proceso de transición hacia una economía de mercado (Hearn, 2012).

\subsection{México}

Pese a que el país norteamericano ha mantenido importantes lazos históricos con China, la presencia de emigrantes procedentes de ese país es no es tan amplia, contando con poco más de 70,000 miembros, dispersos a lo largo de su geografía (Rodríguez, 2012). Salvo en el caso de determinados núcleos en algunas ciudades, especialmente en Mexicali, apenas hay signos notables de su 
presencia. Aunque han dejado un legado cultural a México, sus manifestaciones exteriores son limitadas. La emigración china a México se produjo en gran parte en la época colonial, aportando los chinos de ultramar las habilidades requeridas en ciertas actividades y proporcionando importantes contactos en territorios de Asia con los que se establecieron vínculos comerciales permanentes (Gelber, 2018). Gracias a ellos prosperó durante casi 300 años el llamado "tornaviaje" del Galeón de Manila, permitiendo el flujo de productos chinos en el continente americano y el envío de metales preciosos desde México a China, si bien mediante rutas indirectas desde las Islas Filipinas. Es difícil hablar de una colonia china en México, puesto que la emigración se produjo desde puntos diferentes, con poca comprensión mutua entre sus miembros y sin desarrollar elementos que pudieran favorecer una identidad común. Además, ésta fue una comunidad que sufrió prejuicios, actos de discriminación y en ocasiones deportaciones o persecuciones cruentas (Yankelevich, 2004). Pese a intentos recientes de inclusión en la sociedad mexicana, no puede decirse que haya quedado atrás esa actitud hostil a lo largo de todo el país.

\section{Comunidades chinas y transnacionalismo en América Latina}

La distancia cultural tan amplia entre las culturas de América Latina y de China, así como el limitado conocimiento mutuo, pueden proyectar una imagen monolítica de la inmigración china y de quienes arribaron desde el país asiático al continente americano. Sin embargo, son notables las diferencias entre los emigrantes chinos y entre las comunidades que fueron estableciendo a lo largo de la región. Además de las diferencias externas, existen aspectos de la relación entre aquellos grupos respecto a la madre patria y a los países que los hospedan que son distintivos en cada país, aunque cabe mencionar que el auge de la RPC está teniendo un doble impacto en el transnacionalismo de las comunidades establecidas en la región latinoamericana. De una parte, se fortalecen los vínculos de sus organizaciones con el Gobierno chino, mientras que por otra, se observa "un resurgimiento o reafirmación de la identidad étnica" y sus elementos (Portes \& Armony, 2016). Seguidamente presentamos tales elementos, junto con un sucinto análisis segregado por país, conforme a la sección previamente señalada. Es decir: Perú, Venezuela, Brasil, Panamá, Argentina, Cuba y México. 


\subsection{Familia, asociaciones y comercio en Perú}

Además de tener la mayor población de origen chino asentada en la región, Perú cuenta con la comunidad más organizada para la promoción de los intereses de sus miembros, sean los de arribo reciente o los ya asentados en el país. La comunidad logra esa cohesión mediante tres mecanismos principales: la familia, las asociaciones y el comercio (Rodríguez, 2000). La familia probablemente sea la piedra angular, ya que impone valores y lealtades que difícilmente pudieran exigirse por otros medios. La familia se sustenta en códigos culturales compartidos desde la infancia que se extienden a los integrantes de grandes grupos familiares que han quedado divididos por un océano, pero que pueden mantener lazos que perduran en el tiempo (Tamagno \& Velásquez, 2016). El comercio ha sido otra herramienta vital para brindar protección a los inmigrantes recién llegados y dotar al grupo del poder económico necesario para su movilidad social (Recabarren, 2014). La lealtad entre sus miembros y hacia la madre patria ha dotado a la comunidad local con la versatilidad para mantener vínculos con China, independientemente de quién la gobernara.

La ausencia de fisuras fortalece la representación de la comunidad en la sociedad peruana a través de asociaciones que gozan de prestigio social, siendo la Asociación de Empresas Chinas en el Perú la de mayor influencia (Tamagno \& Velásquez, 2016). Tanto ésta como otras asociaciones tejen una red de influencias en múltiples direcciones, y convierten a los inmigrantes de origen chino en actores importantes en la sociedad peruana. Las asociaciones han ido adaptándose a las nuevas realidades y en la actualidad colaboran con la representación diplomática de la República Popular China en la promoción de la relación bilateral. Por último, Perú proporciona un ejemplo de las diferencias entre las redes familiares de los inmigrantes de las provincias chinas de Fujian \& Cantón (Villalever \& Rubio, 2019).

\subsection{Crisis en Venezuela}

Venezuela alberga una de las comunidades más grandes de América Latina. A pesar de su importante presencia, los chinos étnicos no han podido aprovechar ni su número ni los lazos con la madre patria (Cornejo \& Navarro, 2010). Las estadísticas oficiales no tienen en cuenta a la mayoría de los miembros, lo que minimiza su capacidad de impacto en la política local. Al principio, las nuevas relaciones bilaterales entre China y Venezuela abrieron 
la puerta a proyectos y apoyo financiero, pero esa dinámica parece haberse detenido por la inestabilidad política. Durante la presidencia de Hugo Chávez los lazos formales entre los dos países fueron en aumento y la comunidad se benefició de las inversiones masivas en la industria energética y el desarrollo de infraestructura. El sector turístico también atrajo a turistas chinos cuando Venezuela obtuvo en el año 2006 el EDA (Estado de destino aprobado) por parte del Gobierno chino (Jing, 2012).

Pese a sus inmensas reservas petroleras, Venezuela se encuentra inmersa en una crisis crónica de inestabilidad, azotada por constantes decisiones en perjuicio de la inversión extranjera, demora o falta de pagos (Rosales, 2018) y la hostilidad hacia la población china de origen étnico local. En consecuencia, los flujos masivos de inversión han disminuido y los proyectos son analizados desde una óptica empresarial, de la que pueda excluirse la prevalencia de decisiones con fundamentos políticos sobre las económicas o que respeten criterios de eficiencia.

\subsection{La relación trilateral en Brasil}

La presencia china en el exterior suele tener dos protagonistas: la comunidad inmigrante y la nación anfitriona. En Brasil, en cambio, hay un tercer actor relevante: la comunidad sino-brasileña. La inmigración china en Brasil es un fenómeno antiguo y a lo largo de los años creó fuertes lazos entre los migrantes establecidos, la sociedad de acogida y la madre patria. Una larga experiencia en el trato con el gobierno y con el pueblo brasileño ha permitido a los líderes construir lazos sólidos con la sociedad local. Es por ello que los chinos de ultramar han generado en Brasil un vínculo sólido con las autoridades e instituciones prominentes (Jing, 2012).

Esta comunidad es muy activa en la promoción del idioma y la cultura china, creando así una imagen positiva entre los brasileños, por lo que, a diferencia de la mayoría de las personas en otros países, muchos brasileños ven esta relación como beneficiosa para ambas partes (Da Silva, 2015). Además, la comunidad publicita cuidadosamente las fortalezas del modelo de desarrollo económico de China y su nueva riqueza, y apoya proyectos comerciales en ambos países, aunque las empresas chinas enfrentan varias dificultades a nivel burocrático (Moreno, 2015). El equilibrio entre los dos gobiernos y la comunidad local china es difícil de encontrar en otras latitudes, por lo que 
Brasil representa un caso ejemplar de integración y armonía entre los diferentes actores involucrados.

\subsection{Panamá: la división de dos océanos y... dos comunidades}

Para algunos expertos conquistar Panamá significa poner un pie en el "patio trasero estadounidense” (Paladini, 2011). Tras la restitución del canal por parte de Estados Unidos al país centroamericano en 1999, todas las instalaciones y operaciones quedaron bajo la administración del Gobierno local, por lo que Panamá comenzó a buscar nuevas asociaciones, incluyendo a China (Mellander, 1999). Inmediatamente siguieron importantes inversiones del país asiático. Los estrategas chinos tienen un interés adicional en construir una relación duradera con Panamá. De hecho, la RPC está jugando un juego geopolítico contra Taiwán en Centroamérica y el Caribe, y recientemente Panamá ha pasado a engrosar la lista de países latinoamericanos que reconocen a la RPC en detrimento de Taiwán como legítimo representante de la nación y el Estado chino. La denominada "provincia rebelde" había asentado una relación estable a lo largo de los años y un acercamiento a la sociedad local mediante la colaboración artística y el acercamiento entre panameños y la población étnica china (Hua, 2002). Esa relación amistosa, sin embargo, no pudo frenar la presión del poderío económico de la RPC.

La perspectiva de importantes inversiones en infraestructura y la posibilidad de que Panamá se convierta en una plataforma logística para toda la región están reforzando las incipientes relaciones entre los gobiernos de Pekín y Panamá. Aunque la balanza se inclina claramente a favor del Gobierno chino, persiste el poder económico de aquella parte de la comunidad favorable a Taiwán (Dussel, 2019), por lo que en Panamá se observa la división entre dos grupos con intereses divergentes.

\subsection{Comunidades dispersas en Argentina}

A través del tiempo, y sobre todo en épocas recientes, Argentina ha tenido flujos de migración china importantes. Sin embargo, no ha llegado a consolidarse una comunidad que pueda mostrar cohesión y obtener una representación política adecuada. Históricamente la comunidad taiwanesa en el país austral ganó una mejor aceptación por parte de los sectores pudientes de la sociedad, lo que de alguna manera limitó los esfuerzos de la RPC (Marrero, 2016). 
En la actualidad, varias organizaciones tienen fuertes lazos con la Embajada de China, como sucede con la Unión de Residentes Chinos en Argentina. Esta asociación tiene conexiones directas con varias instituciones chinas y también desempeña un papel activo en las visitas de políticos e inversores chinos (Dangdai, 2014). Una evaluación inicial muestra el transnacionalismo chino en este país como un aparente fracaso. Puede interpretarse de esa forma, debido a la histórica falta de organización de la comunidad, pero probablemente se trate de una situación temporal, puesto que ya se están produciendo diferentes dinámicas y el músculo económico de la RPC probablemente cambiará la situación (Grimson et al., 2016).

\subsection{El peso económico de los chinos de ultramar en Cuba}

El origen histórico de los chinos étnicos en Cuba es peculiar, pues se instalaron en el país caribeño después de ser contratados para sustituir el trabajo esclavo en las plantaciones y en diferentes proyectos de construcción (Basurto, 2001). Los trabajadores chinos se dispersaron por toda la isla, aunque una comunidad relativamente grande se estableció en La Habana. Vivieron y se reunieron en Chinatown o Barrio Chino de la ciudad capital, y pronto pudieron luchar contra la discriminación y la esclavitud. La comunidad fue particularmente exitosa en el sector minorista, controlando tiendas y diferentes actividades económicas en la ciudad (Chuffat, 1927). Sin embargo, la prosperidad llegó a un abrupto final en la década de 1960, cuando Fidel Castro nacionalizó todas las propiedades de los ciudadanos de origen chino (Hearn, 2016). Incluso antes de la revolución los inmigrantes chinos despertaron sospechas entre sus vecinos, pues eran vistos como extraños, viviendo en comunidades marginadas y en gran medida al margen de la ley. La revolución afectó enormemente sus intereses comerciales y la comunidad se vio obligada a aceptar el estricto control impuesto por el Estado socialista (Díaz, 2008). El colapso de la Unión Soviética y el surgimiento de China como potencia mundial fueron testigos de un renovado interés hacia esos migrantes, de manera que en la década de 1990 pudieron obtener los primeros permisos para realizar actividades empresariales (Lehoczki, 2012).

Esta comunidad desempeña un papel relevante tanto en la política local como en la relación bilateral. Actualmente la RPC es una activa promotora de actividades culturales en el barrio chino, lo que a su vez ha despertado el interés de empresarios dispuestos a apoyar negocios con temas chinos en el 
área (Yongnian, 2010). Aunque no se reconoce formalmente, la comunidad goza de un estatus privilegiado en asuntos comerciales.

\subsection{La hostilidad contra los chinos de ultramar en México}

El caso de la comunidad china en México es singular, debido a su escasa presencia y la falta de representatividad ante la sociedad y el Gobierno local. Pese a la creciente importancia del país asiático y el potencial de inversión que representa, ciudadanos de origen chino, los ya residentes o incluso los turistas que arriban, encuentran el desdén o en ocasiones la hostilidad de la población (Gómez, 2017). La raíz de esta situación probablemente se encuentre en la fragmentación y dispersión de los grupos de inmigrantes, lo que no favoreció una relación duradera con la madre patria. Sin embargo, las crecientes oportunidades comerciales que surgen últimamente entre ambas naciones muestran la necesidad de un compromiso más fuerte de las asociaciones y su contribución esperada para romper las barreras culturales y la animosidad.

Algunas de las asociaciones están formadas por inmigrantes recientes, con un estatus social más alto, carreras profesionales y medios económicos. Su mediación se centra ahora en cambiar la percepción de China en México a través de la promoción de la cultura y el idioma, e incluso la Embajada china tiene interés en una mayor interacción con las diferentes asociaciones (Martínez \& Dussel, 2016). La naturaleza de estas asociaciones es diversa: en algunos casos han sido creadas directamente por el Gobierno chino, mientras que en otros casos no cuentan con el apoyo de instituciones extranjeras o incluso conexiones con la RPC. Se dan casos de quienes dicen representar a la comunidad china, pero tienen intereses divergentes y ligados al interés de empresas maquiladoras donde trabajan (Hearn, 2016).

\section{Metodología y resultados}

En las secciones anteriores se presentaron descripciones someras de la presencia de las comunidades chinas en la región, así como sus elementos distintivos. A continuación, buscamos entender en qué medida éstas favorecen los intereses o no de la RPC. Para ello aislamos ciertos factores de referencia que interpretamos como representativos de la importancia de los chinos de ultramar en un determinado país y el avance en las relaciones diplomáticas y económicas de China en esa nación. Tomamos como referencia una propuesta 
de metodología para medir la contribución de cada país al proyecto de la Nueva Ruta de la Seda (Valderrey, Montoya \& Sánchez, 2019), de la que segregamos dos factores: la coordinación de políticas mutuas y los vínculos personales entre la población de cada país y la RPC.

La información sobre el primer factor lo identificamos mediante la firma de acuerdos comerciales de cada país con China, junto al número de visitas presidenciales, tanto de su presidente a la RPC, como las de Xi Jinping a ese país. El segundo factor lo estimamos con base en indicadores internacionales de movilidad y en el número de Institutos Confucio para cada país seleccionado. El tercer factor lo recabamos del desarrollo de los vínculos comerciales bilaterales, refiriéndonos a las importaciones y exportaciones con China. Agregamos un cuarto factor de inversión, incluyendo la inversión directa desde China y la recepción de financiamiento chino en el país en cuestión. Por último, incluimos la variable mercado, compuesta por la población total y el PIB de esa nación. De esa forma, se pueden comparar las siguientes cinco variables de colaboración: 1) coordinación de políticas; 2) vínculos personales; 3) intercambio comercial; 4) inversión, y 5) mercados. A continuación describimos de manera sucinta cada una de las variables, presentamos sus correspondientes valores e indicamos la forma de asignar puntos a cada factor.

\subsection{Coordinación de políticas}

La nueva estrategia internacional china está fundamentada en la formulación de objetivos claros que son plasmados en acuerdos oficiales y refrendados con visitas del más alto nivel. Por tanto, escogimos dos factores para esta variable: la existencia de un tratado de libre comercio y el número de visitas del más alto nivel entre los respectivos gobiernos (véase tabla 1 ). Con la presidencia de Xi Jinping se abre un periodo de expansión en el que el mandatario se involucra directamente para garantizar el éxito de los diferentes proyectos, especialmente el de la Nueva Ruta de la Seda. Muchas de las visitas del presidente han servido para reafirmar las intenciones de colaboración por la parte china. 
Tabla 1

Coordinación de políticas

\begin{tabular}{l|c|c|c|c}
\hline \multirow{2}{*}{ Diáspora } & \multicolumn{2}{|c|}{ TLC con China } & \multicolumn{2}{c}{$\begin{array}{c}\text { Visitas de alto } \\
\text { rango }\end{array}$} \\
\cline { 2 - 5 } & Datos & Punt & Datos & Punt \\
\hline Perú & TLC & 5.00 & 4 & 2.50 \\
\hline Venezuela & No & 0.00 & 4 & 2.50 \\
\hline Brasil & No & 0.00 & 8 & 5.00 \\
\hline Argentina & No & 0.00 & 5 & 3.13 \\
\hline Panamá & $\begin{array}{c}\text { TLC } \\
\text { (Neg) }\end{array}$ & 3.00 & 2 & 1.25 \\
\hline
\end{tabular}

Resultado TLC con RPC

$\mathrm{TLC}=5$ puntos

TLC Neg (negociación) $=3$ puntos

TLC Con (consideración) $=1$ punto

\begin{tabular}{l|c|c|c|c}
\hline Diáspora & \multicolumn{2}{|c|}{ TLC con China } & \multicolumn{2}{c}{$\begin{array}{c}\text { Visitas de alto } \\
\text { rango }\end{array}$} \\
\cline { 2 - 5 } & Datos & Punt & Datos & Punt \\
\hline México & No & 0.00 & 5 & 3.13 \\
\hline Colombia & $\begin{array}{c}\text { TLC } \\
\text { (Con) }\end{array}$ & 1.00 & 1 & 0.63 \\
\hline Chile & TLC & 5.00 & 4 & 2.50 \\
\hline Ecuador & No & 0.00 & 4 & 2.50 \\
\hline Bolivia & No & 0.00 & 1 & 0.63 \\
\hline
\end{tabular}

Resultado visitas de alto rango con $\mathrm{Xi}$ Jinping

Incluye monarcas, presidentes, primeros ministros, etc.

\begin{tabular}{l} 
Resultado = número de visitas / 8 × 5 \\
\hline 8 visitas, máximo registrado en Brasil = 5 \\
puntos
\end{tabular}

Fuente: elaboración propia.

Chile y Perú tienen actualmente un tratado de libre comercio con China, mientras que Panamá se encuentra en el proceso de negociación y Colombia lo está considerando. En término de visitas de alto rango el número de éstas parece obedecer principalmente al tamaño del mercado. Destacan, por ejemplo, los encuentros con Brasil, México y Argentina, y quedan algo más equilibradas las visitas de alto rango con Perú, Venezuela, Chile y Ecuador.

\subsection{Vínculos personales}

Pese a que el tema central de esta investigación gira sobre los vínculos y las acciones coordinadas entre China y los chinos de ultramar, es sumamente difícil establecer parámetros con los cuales evaluar esos vínculos. Ante la imposibilidad de tener cifras creíbles sobre el número de sus miembros en cada país, decidimos integrar dos factores en la variable de vínculos, la movilidad internacional y el número de Institutos Confucio. El primer factor puede parecer banal, pero no lo es, especialmente cuando se estudian poblaciones como las asentadas en Perú, con tráfico constante entre los chinos de ultramar 
y los parientes que quedaron atrás. El segundo factor parece también revestir una importancia secundaria, pero en realidad los Institutos Confucio están adquiriendo un papel protagónico a la hora de propagar los valores y la milenaria cultura china. La tabla 2 recoge la distribución de puntos en función de los vínculos de las comunidades.

\section{Tabla 2}

Vínculos de las comunidades

\begin{tabular}{|c|c|c|c|c|}
\hline \multirow[t]{2}{*}{ Diáspora } & \multicolumn{2}{|c|}{$\begin{array}{c}\text { Movilidad } \\
\text { internacional }\end{array}$} & \multicolumn{2}{|c|}{$\begin{array}{l}\text { Institutos } \\
\text { Confucio }\end{array}$} \\
\hline & Datos & Punt & Datos & Punt \\
\hline Perú & 134 & 3.83 & 4 & 2.00 \\
\hline Venezuela & 138 & 3.94 & 1 & 0.50 \\
\hline Brasil & 171 & 4.89 & 10 & 5.00 \\
\hline Argentina & 170 & 4.86 & 2 & 1.00 \\
\hline Panamá & 141 & 4.03 & 1 & 0.50 \\
\hline \multicolumn{5}{|c|}{ Resultado movilidad internacional } \\
\hline \multicolumn{5}{|c|}{$\begin{array}{l}\text { Resultado = índice de pasaportes Henley } \\
/ 175 \times 5\end{array}$} \\
\hline \multicolumn{5}{|c|}{$\begin{array}{l}175 \text { países (pasaporte de Chile) }=5 \\
\text { puntos }\end{array}$} \\
\hline
\end{tabular}

\begin{tabular}{l|c|c|c|c}
\hline \multirow{2}{*}{ Diáspora } & \multicolumn{2}{|c|}{$\begin{array}{c}\text { Movilidad } \\
\text { internacional }\end{array}$} & \multicolumn{2}{c}{$\begin{array}{c}\text { Institutos } \\
\text { Confucio }\end{array}$} \\
\cline { 2 - 5 } & Datos & Punt & Datos & Punt \\
\hline México & 158 & 4.51 & 5 & 2.50 \\
\hline Colombia & 127 & 3.63 & 3 & 1.50 \\
\hline Chile & 175 & 5.00 & 2 & 1.00 \\
\hline Ecuador & 93 & 2.66 & 1 & 0.50 \\
\hline Bolivia & 79 & 2.26 & 1 & 0.50 \\
\hline
\end{tabular}

Resultado número de Institutos Confucio

Resultado = Institutos Confucio / $10 \times 5$

Institutos Confucio en Brasil $=5$ puntos

Fuente: elaboración propia.

Ante la falta de fuentes confiables se construyó el factor movilidad internacional con base en la facilidad para viajar a un mayor número de países. La definición de este factor es claramente mejorable y pudiera pensarse en otros, como un registro de inmigrantes, por ejemplo, pero la información no está disponible o es de escasa confiabilidad. El segundo factor es claramente identificable, puesto que los Institutos Confucio tienen el respaldo claro de la RPC, excluyéndose escuelas de idiomas, centros culturales o demás, que no cuenten con el registro y el apoyo expreso del Gobierno chino.

\subsection{Intercambio comercial}

En secciones anteriores se ha mencionado la relación de la RPC con las comunidades étnicas chinas en algunos países. Aunque cabría pensar que el intercambio comercial entre China y los países analizados se mueve en clara 
coordinación con las comunidades étnicas de aquel país, no existe tal relación. México, por ejemplo, tiene un volumen de importaciones considerablemente alto, al menos en términos comparativos, pero la presencia de las comunidades chinas en ese país no es tan relevante. No existe por tanto una relación visible entre el intercambio comercial y la presencia de los chinos de ultramar, tal y como se aprecia en la tabla 3.

Tabla 3

Intercambio comercial

\begin{tabular}{|c|c|c|c|c|c|c|c|c|c|}
\hline \multirow[t]{2}{*}{ Diáspora } & \multicolumn{2}{|c|}{ Importaciones } & \multicolumn{2}{|c|}{ Exportaciones } & \multirow[t]{2}{*}{ Diáspora } & \multicolumn{2}{|c|}{ Importaciones } & \multicolumn{2}{|c|}{ Exportaciones } \\
\hline & Datos & Punt & Datos & Punt & & Datos & Punt & Datos & Punt \\
\hline Perú & 8.925 & 0.67 & 7.025 & 37 & Mé & 66.2 & 5.00 & 5.979 & 0.74 \\
\hline Venez & 5.657 & 0.43 & 11.320 & 1.39 & $\mathrm{Co}$ & 11 & 0.89 & 5.755 & 0.71 \\
\hline Brasil & 37.341 & 2.82 & 40.616 & 5.00 & Chile & 15.1 & 1.14 & 18.828 & 2.32 \\
\hline Argentina & 10.703 & 0.81 & 4.462 & 0.59 & $\mathrm{Ecl}$ & 4.5 & 0.35 & 501 & 0.05 \\
\hline Panamá & 1.114 & 0.08 & 69 & 0.01 & Bolivia & 1.811 & 0.14 & 434 & 0.05 \\
\hline \multicolumn{5}{|c|}{$\begin{array}{l}\text { Resultado Importaciones desde China, año } \\
2014\end{array}$} & \multicolumn{5}{|c|}{ Resultado Exportaciones a China, año 2014} \\
\hline \multicolumn{5}{|c|}{$\begin{array}{l}\text { Resultado = Importaciones en millones de } \\
\text { USD / } 66.256 \text { x } 5\end{array}$} & \multicolumn{5}{|c|}{$\begin{array}{l}\text { Resultado = Exportaciones en millones de } \\
\text { USD / } 40.616 \times 5\end{array}$} \\
\hline \multicolumn{5}{|c|}{$\begin{array}{l}\text { Valor máximo: México con } 66.256 \text { millones } \\
\text { USD = } 5 \text { Puntos }\end{array}$} & \multicolumn{5}{|c|}{$\begin{array}{l}\text { Valor máximo: Brasil con } 40.616 \text { millones } \\
\text { USD = } 5 \text { Puntos }\end{array}$} \\
\hline
\end{tabular}

Fuente: elaboración propia.

Pese a que México se ha ido posicionando como un importante socio para la RPC, ésta no presta demasiada importancia a la situación. No hay un acercamiento evidente del Gobierno chino con el mexicano y la sucesión de encuentros de alto nivel no resulta trascendente.

\subsection{Inversión}

Una situación sorprendente es la relacionada con la inversión, ya que ésta se produce conforme a las oportunidades existentes y no es moldeada por las comunidades locales. En este rubro destacan Perú, en términos de inversión, y Venezuela en términos de financiamiento, aunque conviene señalar que probablemente este último no constituya un factor estabilizador en la relación 
bilateral, ya que añade presión a la situación. Los resultados se muestran en la tabla 4.

Tabla 4

Inversión

\begin{tabular}{|c|c|c|c|c|c|c|c|c|c|}
\hline \multirow[t]{2}{*}{ Diáspora } & \multicolumn{2}{|c|}{ Inversión } & \multicolumn{2}{|c|}{ Financiamiento } & \multirow[t]{2}{*}{ Diáspora } & \multicolumn{2}{|c|}{ Inversión } & \multicolumn{2}{|c|}{ Financiamiento } \\
\hline & Datos & Punt & Datos & Punt & & Datos & Punt & Datos & Punt \\
\hline Perú & 3993,90 & 5.00 & 50,00 & 0.00 & Mé & 496,28 & 0.62 & 1000,00 & 0.08 \\
\hline Venezu & 2271,84 & 2.84 & 2200,00 & 5.00 & Colc & 285,40 & 0.36 & 0,00 & 0.00 \\
\hline Brasil & 1296,52 & 1.62 & 36800,00 & 2.96 & $\mathrm{Ch}$ & 278,11 & 0.35 & 150,00 & 0.01 \\
\hline Argentina & 1624,00 & 2.03 & 15300,00 & 1.23 & & 1115,80 & 1.4 & 17400,00 & 1.40 \\
\hline Panamá & 254,41 & 0.32 & 0,00 & 0.00 & Bolivia & 171,84 & 0.26 & 3500,00 & 0.28 \\
\hline \multicolumn{5}{|c|}{ Resultado inversión directa oficial de China } & \multicolumn{5}{|c|}{$\begin{array}{l}\text { Resultado financiamiento oficial desde } \\
\text { China }\end{array}$} \\
\hline \multicolumn{5}{|c|}{$\begin{array}{l}\text { Resultado = IED en millones USD / 3993,9 } \\
\text { x } 5\end{array}$} & \multicolumn{5}{|c|}{$\begin{array}{l}\text { Resultado = financiamiento en millones } \\
\text { USD / } 62200 \text { x } 5\end{array}$} \\
\hline \multicolumn{5}{|c|}{$\begin{array}{l}\text { Valor máximo: Perú con 3993,9 millones de } \\
\text { USD = } 5 \text { puntos }\end{array}$} & \multicolumn{5}{|c|}{$\begin{array}{l}\text { Valor máximo: Venezuela con } 62200 \\
\text { millones de USD }=5 \text { puntos }\end{array}$} \\
\hline
\end{tabular}

Fuente: elaboración propia.

En el caso de Perú, la inversión alcanza su valor máximo, con una distancia demasiado notable frente a Venezuela y los demás países. El país con la comunidad más importante, Perú, no recibe hasta la fecha ningún tipo de financiamiento, mientras que las cifras tan elevadas de inversión en Venezuela quedan muy por encima de los demás países. Un análisis más detallado puede poner sobre la mesa el rezago en la industria del petróleo en ese país, con la consiguiente necesidad de capitales e inversiones.

\subsection{Mercados}

La variable "mercados" permite observar la importancia que la RPC presta o no a sus comunidades. Brasil ocupa claramente el primer lugar a la hora de combinar el total de su población con su PIB. México le sigue, y de manera muy distante Argentina, mientras que los demás países no alcanzan valores relevantes en esta comparación en los valores que aparecen en la tabla 5. 
Tabla 5

Mercados

\begin{tabular}{|c|c|c|c|c|c|c|c|c|c|}
\hline \multirow[t]{2}{*}{ Diáspora } & \multicolumn{2}{|c|}{ Población } & \multicolumn{2}{|l|}{ PIB } & \multirow[t]{2}{*}{ Diáspora } & \multicolumn{2}{|c|}{ Población } & \multicolumn{2}{|l|}{ PIB } \\
\hline & Datos & Punt & Datos & Punt & & Datos & Punt & Datos & Punt \\
\hline Perú & 31,99 & 0.76 & 225,37 & 0.60 & México & 124,74 & 2.98 & 1222,05 & 3.27 \\
\hline Venezuela & 28,87 & 0.69 & 98,43 & 0.26 & Colomb & 49,83 & 1.19 & 330,97 & 0.86 \\
\hline Brasil & 209,47 & 5.00 & 1867,81 & 5.00 & Chile & 18,73 & 0.45 & 298,18 & 0.80 \\
\hline Argentina & 44,56 & 1.06 & 637,59 & 1.71 & Ecuador & 17,02 & 0.41 & 108,40 & 0.29 \\
\hline Panamá & 4,16 & 0.1 & 65,05 & 0.1 & Bolivia & 11,35 & 0.27 & 40,29 & 0. \\
\hline \multicolumn{5}{|c|}{$\begin{array}{l}\text { Resultado población en millones de } \\
\text { habitantes }\end{array}$} & \multicolumn{5}{|c|}{ Resultado PIB (2017) en millones USD } \\
\hline \multicolumn{5}{|c|}{$\begin{array}{l}\text { Resultado = millones de habitantes / } \\
209,47 \times 5\end{array}$} & \multicolumn{5}{|c|}{$\begin{array}{l}\text { Resultado = PIB en millones USD / 1867,81 } \\
\text { x } 5\end{array}$} \\
\hline \multicolumn{5}{|c|}{$\begin{array}{l}\text { Valor máximo: 209, } 47 \text { millones en Brasil = } \\
5 \text { puntos }\end{array}$} & \multicolumn{5}{|c|}{$\begin{array}{l}\text { Valor máximo: } 1867,8 \text { millones de USD en } \\
\text { Brasil = } 5 \text { puntos }\end{array}$} \\
\hline
\end{tabular}

Fuente: elaboración propia.

Los dos gigantes en términos de población, Brasil y México, quedan muy distanciados de las demás naciones. Parece existir una correlación entre población y territorio, conforme dicta el sentido común.

\subsection{Metodología}

La tabla 6 recoge la información sobre las cinco variables de colaboración del grupo denominado "Diáspora", que integra a los países con mayor presencia de los chinos de ultramar, mientras que la 7 sintetiza los resultados del segundo grupo, el de los países más importantes de América Latina que no están incluidos en la primera muestra. 
Tabla 6

Variables de colaboración para los países de la diáspora china

\begin{tabular}{|c|c|c|c|c|c|c|c|c|c|c|c|}
\hline \multirow{2}{*}{$\begin{array}{l}\text { Diáspora } \\
\text { china }\end{array}$} & \multicolumn{2}{|c|}{ Coordinación } & \multicolumn{2}{|c|}{ Vínculos } & \multicolumn{2}{|c|}{ Intercambio } & \multicolumn{2}{|c|}{ Inversión } & \multicolumn{2}{|c|}{ Mercados } & \multirow{2}{*}{\begin{tabular}{|c|} 
Total \\
$100 / 100$
\end{tabular}} \\
\hline & Trata & Presi & Movil & Confu & Impor & Expor & Inver & Finan & Pobla & Produ & \\
\hline Perú & 5.00 & 2.50 & 3.83 & 2.00 & 67 & .87 & 5.00 & 00 & 0.76 & 0.60 & 21.23 \\
\hline Vener & 0.00 & 2.50 & 3.94 & 0.50 & 0.43 & 1.39 & 2.84 & U & 0.69 & .26 & 17.55 \\
\hline Brasi & 0.00 & 5.00 & 4.89 & 5.00 & 2 & 5.00 & 1.62 & 2.9 & 5.00 & .00 & 7.29 \\
\hline Arge & 0.00 & 3.13 & 4.86 & 1.00 & 0.81 & 0.59 & 2.03 & 1.23 & 1.06 & 1.71 & 16.42 \\
\hline Pan & 3.00 & 1.25 & 4.03 & 0.50 & 0.08 & 0.01 & 0.32 & 0.00 & 0.1 & 0.17 & 9.46 \\
\hline Prom & 1.60 & 2.88 & 4.31 & 1.80 & 0. & 1.57 & 2.36 & 1.84 & 1.52 & 1.55 & 39 \\
\hline \multicolumn{6}{|c|}{ Trata $=$ tratado de libre comercio con China } & \multicolumn{6}{|c|}{ Expor $=$ exportaciones a China } \\
\hline \multicolumn{6}{|c|}{$\begin{array}{l}\text { Presi = visitas de alto rango con Xi Jinping, } \\
2013-2018\end{array}$} & \multicolumn{6}{|c|}{ Inver = inversión directa oficial de China } \\
\hline \multicolumn{6}{|c|}{$\begin{array}{l}\text { Movil = número de países de acceso con su } \\
\text { pasaporte }\end{array}$} & \multicolumn{6}{|c|}{$\begin{array}{l}\text { Finan = financiamiento oficial desde } \\
\text { China }\end{array}$} \\
\hline \multicolumn{6}{|c|}{ Confu = Número de Institutos Confucio } & \multicolumn{6}{|c|}{ Pobla = población total del país } \\
\hline \multicolumn{6}{|c|}{ Impor $=$ importaciones desde China } & \multicolumn{6}{|c|}{ Produ = producto interior bruto (PIB) } \\
\hline
\end{tabular}

Fuente: elaboración propia.

Para cada una de las naciones se realiza la sumatoria de los resultados conforme a las cinco variables. Brasil tiene una puntuación que es casi la doble del promedio, del que solo están por encima el país mencionado y Perú, aunque muy ligeramente. Los demás países caen ligeramente por debajo del promedio, salvo en el caso de Panamá, donde la puntuación es extraordinariamente baja.

En la tabla 7 se presentan los resultados de las variables de colaboración para los países de América Latina no incluidos en la muestra anterior. México destaca por encima de los demás, aunque lo hace con valores ligeramente superiores a los del otro grupo. El promedio de éste es notoriamente inferior al primero, llegando casi a la mitad. 
Tabla 7

Variables de colaboración para los países de la región

\begin{tabular}{|c|c|c|c|c|c|c|c|c|c|c|c|}
\hline \multirow[t]{2}{*}{ Diáspora } & \multicolumn{2}{|c|}{ Coordinación } & \multicolumn{2}{|c|}{ Vínculos } & \multicolumn{2}{|c|}{ Intercambio } & \multicolumn{2}{|c|}{ Inversión } & \multicolumn{2}{|c|}{ Mercados } & \multirow{2}{*}{\begin{tabular}{|c|} 
Total \\
$100 / 100$ \\
\end{tabular}} \\
\hline & Trata & Presi & Movil & Confu & Impor & Expor & Inver & Finan & Pobla & Produ & \\
\hline México & 0.00 & 3.13 & 4.51 & 2.50 & 5.00 & 0.74 & 0.62 & 0.08 & 2.98 & 3.27 & 22.83 \\
\hline Colombia & 1.00 & 0.63 & 3.63 & 1.50 & 0.89 & 0.71 & 0.36 & 0.00 & 1.19 & 0.86 & 10.77 \\
\hline Chile & 5.00 & 2.50 & 5.00 & 1.00 & 1.14 & 2.32 & 0.35 & 0.01 & 0.45 & 0.80 & 18.57 \\
\hline Ecuador & 0.00 & 2.50 & 2.66 & 0.50 & 0.35 & 0.06 & 1.40 & 1.40 & 0.41 & 0.29 & 7.07 \\
\hline Bol & 0.00 & 0.63 & 2.26 & 0.50 & 0.14 & 0.05 & 0.26 & 0.28 & 0.27 & 1 & 4.50 \\
\hline Promedio & 1.20 & 1.72 & 3.61 & 1.20 & 1.5 & .78 & 0.60 & 0.35 & 1.06 & & 1 \\
\hline \multicolumn{6}{|c|}{ Trata = tratado de libre comercio con China } & \multicolumn{6}{|c|}{ Expor $=$ exportaciones a China } \\
\hline \multicolumn{6}{|c|}{$\begin{array}{l}\text { Presi = visitas de alto rango con Xi Jinping, } \\
\text { 2013-2018 }\end{array}$} & \multicolumn{6}{|c|}{ Inver = inversión directa oficial de China } \\
\hline \multicolumn{6}{|c|}{$\begin{array}{l}\text { Movil = número de países de acceso con su } \\
\text { pasaporte }\end{array}$} & \multicolumn{6}{|c|}{ Finan = financiamiento oficial desde China } \\
\hline \multicolumn{6}{|c|}{ Confu = número de Institutos Confucio } & \multicolumn{6}{|c|}{ Pobla = población total del país } \\
\hline \multicolumn{6}{|c|}{ Impor $=$ importaciones desde China } & \multicolumn{6}{|c|}{ Produ = producto interior bruto (PIB) } \\
\hline
\end{tabular}

Fuente: elaboración propia.

Chile queda cerca de los valores de México, mientras que en los casos de Colombia, Ecuador y Bolivia, los valores son evidentemente más bajos. El caso de Bolivia es especialmente llamativo por sus resultados tan limitados.

Inicialmente establecimos una prueba de hipótesis para comprobar la diferencia entre las medias de la población entre ambos grupos, entendiendo que si los resultados eran iguales en los dos grupos los comportamientos serían similares en su relación con China. Las dos poblaciones corresponden a: 1) las cinco naciones en América Latina con mayores comunidades de origen chino, y 2) los cinco países que consideramos como los más importantes, al margen de los incluidos en la muestra anterior. Debido a que el tamaño de las muestras no era mayor o igual a 30 preferimos considerar una distribución t-Student con 18 grados de libertad (gl) para tamaños de muestras iguales, utilizando un estimador de desviación estándar combinada con $\mathrm{s}=0.6776$. Por lo tanto, usamos una significancia del $10 \%$ y un coeficiente de confianza del $90 \%$, obteniendo $t_{\frac{\alpha}{2}}, g l 18=1.734$. Con esos valores encontramos un intervalo de confianza para la diferencia de medias de -0.3480 a 2.002. Con el indicio obtenido del intervalo de confianza nos propusimos probar la siguiente hipótesis: 


$$
\begin{aligned}
& \text { Ho: } \mu 1-\mu 2=0 \\
& \text { Ha: } \mu 1-\mu 2 \neq 0
\end{aligned}
$$

Realizamos la prueba $t$ para dos muestras, suponiendo varianzas desiguales, cuyos resultados se muestran en la tabla 8.

\section{Tabla 8}

Prueba $t$ para dos muestras suponiendo varianzas desiguales

\begin{tabular}{l|c|c|c|c|c|c|c|c|c|c}
\hline & Coordinación & \multicolumn{2}{|c|}{ Vínculos } & \multicolumn{2}{c|}{ Comercio } & \multicolumn{2}{c|}{ Inversión } & \multicolumn{2}{c}{ Mercado } \\
\cline { 2 - 13 } & Diá & Reg & Diá & Reg & Diá & Reg & Diá & Reg & Diá & Reg \\
\hline Media & 2.24 & 1.54 & 3.05 & 2.41 & 1.27 & 1.14 & 2.1 & 0.48 & 1.54 & 1.06 \\
\hline Varianza & 3.64 & 2.82 & 3.46 & 2.53 & 2.36 & 2.30 & 3.45 & 0.27 & 3.56 & 1.29 \\
\hline Observaciones & 10 & 10 & 10 & 10 & 10 & 10 & 10 & 10 & 10 & 10 \\
\hline Diferencia* & 0 & & 0 & & 0 & & 0 & & 0 & \\
\hline Grados de libertad & 18 & & 18 & & 18 & & 10 & & 15 & \\
\hline Estadístico $t$ & 0.87 & & 0.84 & & 1.34 & & 2.66 & & 0.68 & \\
\hline $\mathrm{P}(\mathrm{T}<=\mathrm{t})$ una cola & 0.20 & & 0.21 & & 0.43 & & 0.01 & & 0.25 & \\
\hline Valor crítico de t** & 1.33 & & 1.33 & & 1.33 & & 1.37 & & 1.34 & \\
\hline $\mathrm{P}(\mathrm{T}<=\mathrm{t})$ dos colas & 0.40 & & 0.41 & & 0.85 & & 0.03 & & 0.51 & \\
\hline Valor crítico de t** & 1.73 & & 1.73 & & 1.73 & & 1.81 & & 1.75 & \\
\hline
\end{tabular}

*Diferencia hipotética de medias.

${ }^{* *}$ Dos colas.

Diá = diáspora.

Reg = región.

Fuente: elaboración propia.

Seguidamente llevamos a cabo el mismo análisis para las cinco variables del estudio, obteniendo los resultados que mostramos en la tabla 9, basándonos en la hipótesis general de que la diferencia en cada variable asignada al grupo de países de la diáspora y la coordinación promedio asignada a los países de la región es cero. En la misma tabla se presenta también el detalle de cada estadístico de prueba, valor crítico de una cola, valor crítico de dos colas, el resultado de la hipótesis para cada variable y la conclusión correspondiente con un $90 \%$ de confianza. 
Tabla 9

Resultados del análisis de las cinco variables

\begin{tabular}{l|l|l|l|l|l}
\hline & Coordinación & Vínculos & Comercio & Inversión & Mercados \\
\hline $\begin{array}{l}\text { Estadístico de } \\
\text { prueba }\end{array}$ & 0.8694 & 0.8383 & 1.3368 & 2.6606 & 0.6780 \\
\hline $\begin{array}{l}\text { Valor crítico de una } \\
\text { cola }\end{array}$ & 1.3304 & 1.3304 & 1.3304 & 1.3722 & 1.3406 \\
\hline $\begin{array}{l}\text { Valor crítico de dos } \\
\text { colas }\end{array}$ & 1.7341 & 1.7341 & 1.7341 & 1.8125 & 1.7531 \\
\hline $\begin{array}{l}\text { Resultado de la } \\
\text { hipótesis }\end{array}$ & $\begin{array}{l}\text { Se rechaza } \\
\text { Ho }\end{array}$ & $\begin{array}{l}\text { Se rechaza } \\
\text { Ho }\end{array}$ & $\begin{array}{l}\text { No se } \\
\text { rechaza Ho }\end{array}$ & $\begin{array}{l}\text { No se } \\
\text { rechaza Ho }\end{array}$ & $\begin{array}{l}\text { Se rechaza } \\
\text { Ho }\end{array}$ \\
\hline Conclusión* & $\begin{array}{l}\text { No es la } \\
\text { misma } \\
\text { población }\end{array}$ & $\begin{array}{l}\text { No es la } \\
\text { misma } \\
\text { población }\end{array}$ & $\begin{array}{l}\text { Misma } \\
\text { población }\end{array}$ & $\begin{array}{l}\text { Misma } \\
\text { población }\end{array}$ & $\begin{array}{l}\text { No es la } \\
\text { misma } \\
\text { población }\end{array}$ \\
\hline
\end{tabular}

${ }^{*}$ La conclusión se refiere a que se comportan o no como si ambos grupos fueran la misma población.

Fuente: elaboración propia.

Tras analizar la ponderación de cada variable, se puede considerar que en los casos de comercio e inversión se comportan como la misma población. Sin embargo, en las variables de coordinación vínculos y mercados se puede considerar que los dos grupos no se comportan como la misma población. Las comunidades chinas no parecen tener impacto con la madre patria en lo referente a las exportaciones e importaciones, así como en las decisiones de inversión. Sin embargo, las comunidades tienen una aportación significativa en lo referente a los vínculos entre presidentes y la firma de tratados, al igual que ocurre estableciendo vínculos personales y culturales que favorecen el avance de China en América Latina. Otro factor de impacto en la estrategia de China es el tamaño del mercado, representado por la población local y su PIB.

\section{Comentarios finales}

A lo largo de las últimas décadas la presencia de China en América Latina se ha incrementado considerablemente, lo que no es obvio es el papel que puedan haber ejercido las comunidades de origen chino en ese desarrollo. A primera vista el rol histórico de los chinos de ultramar tiene una importancia marginal, con comunidades dispersas a través de la inmensa geografía de la 
región y sin la representatividad suficiente para influir en temas de impacto en las naciones que las albergaron.

Al no tener China un peso importante en la arena internacional durante casi toda la historia de las migraciones de sus ciudadanos en América Latina, simplemente no hubo tal cuestión. Solo algunas comunidades fueron más visibles, como la peruana, pero estuvieron avocadas a la defensa de sus intereses locales, no tanto a constituirse como colaboradores de una potencia extranjera. Por lo tanto, el posible impacto de los chinos de ultramar establecidos en América Latina en la atracción de inversiones del país oriental puede circunscribirse a las últimas tres décadas, aproximadamente. Durante este periodo el Gobierno chino ha perseguido distintos objetivos en la región latinoamericana, entre los que destacan la expansión comercial, el aseguramiento de las materias primas necesarias para sus procesos de manufactura y el fortalecimiento de su presencia en el continente para buscar el reconocimiento como potencia internacional.

En el periodo inmediatamente precedente, tras el fin de la guerra civil y la separación en dos Estados pretendiendo representar a China, la política exterior de la RPC y de Taiwán giró en torno al reconocimiento de cada uno de los bandos por parte de los países latinoamericanos, sin dejar espacio para el avance de ambas. Durante esa época la RPC fue obteniendo paulatinamente el apoyo por parte de organismos internacionales y la inmensa mayoría de las naciones, pero Taiwán supo mantener su reconocimiento en un gran número de países en América Latina. Puesto que el fenómeno de una presencia vigorosa de China en esa zona es muy reciente, nos remitimos a la coyuntura actual para realizar nuestro análisis.

Pudiera afirmarse que el interés geopolítico de la RPC hacia la región latinoamericana ha sido moderado y probablemente dirigido a arrinconar a su gran rival del otro lado del estrecho. La geoeconomía, sin embargo, ha tenido una mayor influencia debido a la vinculación económica que le permitía obtener los recursos minerales necesarios para su producción industrial y, posteriormente, los recursos de agronegocios para su población. Las exportaciones chinas a cada país fueron aumentando, pero solamente la cifra agregada del comercio internacional con todos los países de la región presentaba cifras realmente importantes. Hoy en día las ambiciones del gobierno de Xi Jinping han despertado mayor interés en la región, sobre todo por su posible impacto en la guerra comercial con Estados Unidos y por la extensión del proyecto de la Iniciativa Franja y Ruta (One Belt, One Road) al continente americano, por 
lo que tanto los motivos políticos como los económicos están moldeando la estrategia china en América Latina. Además, el acercamiento entre China y la región latinoamericana adquiere mayor importancia al considerarse la tendencia al comercio intrarregional en la cuenca Asia Pacífico (Paz, 2018), pese a que los acontecimientos registrados en el año 2020 parezcan detenerla temporalmente.

Con el presente trabajo no se pretende agotar la descripción de la diáspora china en la región. Realizamos un análisis comparativo que presentamos entre los países con mayor presencia de chinos de ultramar y los principales países de América Latina que no están incluidos en el primer grupo revela que no existe una clara coordinación entre los países con mayor población de origen chino y su madre patria en función de su intercambio comercial o la inversión china en esas naciones. Sin embargo, la relación es significativa en función de la coordinación de sus gobiernos, los vínculos con la comunidad china establecida en esos países y del tamaño del mercado. En consecuencia, podemos observar que la estrategia del Gobierno chino no está atendiendo suficientemente a sus comunidades de ultramar, al menos en el escenario regional latinoamericano. Podemos afirmar que las comunidades chinas de ultramar ejercen un efecto moderado en la política exterior de China hacia América Latina, pero el Gobierno de la madre patria no les concede gran importancia, aunque las comunidades realizan un esfuerzo para allanar el camino a las empresas chinas que desean establecerse en esos países. No hay por tanto un "caballo de Troya" puesto por los chinos de ultramar para favorecer a su madre patria. Eso sí, las comunidades hacen un esfuerzo de su parte y no debe excluirse la posibilidad de que el Gobierno chino se vuelva más incluyente hacia ellas en sus políticas geoestratégicas y de penetración de mercados latinoamericanos.

\section{Referencias}

Atwell, W. S. (1986). Some observations on the "Seventeenth-century crisis" in China and Japan. The Journal of Asian Studies, 45(2), 223-244. https:// doi.org/10.2307/2055842

Basurto, M. G. (2001). Los chinos de Cuba, apuntes etnográficos de José Baltar Rodríguez. Alteridades, (21), 121-123. https://doi.org/10.24275/ uam/izt/dcsh/alteridades 
Bedinelli, T. \& Veleda, R. (2010). Reclusa e discreta, colônia chinesa se espalha por SP. Folha de Sao Paulo.

Ben-Rafael, E. (2013). Las diásporas transnacionales: ¿una nueva era o un nuevo mito? Revista mexicana de ciencias políticas y sociales, 58(219), 189-223.

Canales, A., Fuentes, J. A., \& De León, C. R. (2019). Desarrollo y migración: desafíos y oportunidades en los países del norte de Centroamérica (LC/ MEX/TS.2019/7). https://www.cepal.org/es/publicaciones/44649-desarrollo-migracion-desafios-oportunidades-paises-norte-centroamerica Chuffat, A. (1927). Apunte histórico de los chinos en Cuba. Molina y Cía.

Conrad, R. (1975). The planter class and the debate over Chinese immigration to Brazil, 1850-1893. International Migration Review, 9(1), 41-55. https:// doi.org/10.1177/019791837500900104

Cornejo, R. (1995). Los chinos en el Sudeste de Asia Consideraciones sobre el estudio de las minorías chinas en Indonesia, Malasia y Tailandia. Estudios de Asia y África, 30(2), 297-318. https://www.jstor.org/stable/40312491

Cornejo, R., \& Navarro, A. (2010). China y América Latina: recursos, mercados y poder global. Nueva Sociedad, 228, 79-99. https://nuso.org/articulo/ china-y-america-latina-recursos-mercados-y-poder-global/

Cuéllar, R. (2012). Geopolítica. Origen del concepto y su evolución. Revista de Relaciones Internacionales de la UNAM, 59, 59-80. http://www.revistas. unam.mx/index.php/rri/article/view/48963

Da Silva, P. (2015) La difusión de la lengua y cultura chinas en Brasil: un hecho político-estratégico. Revista Mundorama.

Dangdai (20 de octubre 2014). El Sueño Chino, presentado en Buenos Aires por el partido Zhi Gong. http://dangdai.com.ar

Díaz, J. (2008). Apuntes sobre las relaciones China-Cuba. Observatorio de la Economía y la Sociedad China, 9. http://www.eumed.net/rev/china/09/ jadv.htm

Dussel, E. (2019). China's Recent Engagement in Latin America and the Caribbean: Current Conditions and Challenges. CECHIMEX/UNAM.

Eng, Y. G. (2013). Los chinos de Cuba, el Caribe y América Latina: un proyecto de investigación sobre el chino latino. En S. Chen, J. Bartels, \& R. Martínez (Eds.), Estudios sobre China desde Latinoamérica: Geopolítica, religión e inmigración. Editores 1.

Fleischer, F. (2012). La diáspora china: un acercamiento a la migración china en Colombia. Revista de Estudios Sociales, (42), 71-79. 
Ford, C. A. (2015). China looks at the west: Identity, global ambitions, and the future of Sino-American relations. University Press of Kentucky.

Gelber, M. H. (2018). Los Chinos de La Chinesca: Destabilizing National Narratives and Uncovering the Forgotten History of the Chinese in Mexico. Senior Projects Spring. https://digitalcommons.bard.edu/senproj_s2018/187

Grillo, R. M. (2013). Emigración italiana a las Américas. Hispanista Escandinava, 2, 66-86.

Grimson, A., Ng, G., \& Denardi, L. (2016). Las organizaciones de inmigrantes chinos en Argentina. Migración y desarrollo, 14(26), 25-73. http://dx.doi. org/10.35533/myd.1426.ag.gn.ld

Gómez, R. (2017). Chinese Mexicans: Mexico's Forgotten and Overlooked Mestizos. History in the Making, 10(1), 4. https://scholarworks.lib.csusb. edu/history-in-the-making/vol10/iss $1 / 4$

Hearn, A. H. (2016). Diaspora and Trust: Cuba, Mexico, and the rise of China. Duke University Press.

Hearn, A. H. (2012). Harnessing the dragon: overseas Chinese entrepreneurs in Mexico and Cuba. The China Quarterly, 209, 111-133. http://dx.doi. org/10.1017/S0305741011001500

The Hong Kong Trade Development Council (HKTDC Research). (18 de febrero de 2018). The Belt and Road Initiative. http://china-trade-research.hktdc. com/business-news/article/The-Belt-and-Road-Initiative/The-Belt-andRoad-Initiative/obor/en/1/1X000000/1X0A36B7.htm

Hua, V. (23 de junio de 2002). Playing the Panama Card: The China-Taiwan Connection. San Francisco Chronicle. https://www.sfgate.com/opinion/ article/Playing-the-Panama-card-The-China-Taiwan-2827189.php

Jiménez, J. (1983). Los chinos en la historia de Cuba, 1847-1930. Editorial de Ciencias Sociales.

Jing, C. (2012). Sobre el papel de los chinos de ultramar en el avance del poder blando de China en Brasil. Orientando Temas de Asia Oriental, Sociedad, Cultura y Economía, (4). https://orientando.uv.mx/index.php/orientando/ article/view/320

Johnston, D. (17 de junio de 1990). Officials Brace for Exodus of Foreigners from Panama. The New York Times. http://www.nytimes.com/1990/06/18/ us/officials-brace-for-exodus-of-foreigners-from-panama.html

Kenley, D. (2013). Construyendo una comunidad imaginada en Cuba: Fraternidad/Lianhe de La Habana, 1938-19441. En R. Martínez (Coord.), Estudios sobre China desde Latinoamérica: Geopolítica, Religión e Inmigración. 
(pp. 183-214). http://www.palabradeclio.com.mx/src_pdf/los_chinos_ de_ultramar_int.pdf

Kim J. (2018). Between cooperation and survival. Social Transformations in Chinese Societies, 14(2), 79-96. http://dx.doi.org/10.1108/ STICS-04-2018-0007

Lares, V. (21 de Abril de 2007). La colonia china más grande de Venezuela vive en Valencia, capital del estado Carabobo. El Tiempo. http://www.eltiempo. com/archivo/documento/CMS-3522877

Lehoczki, B. (2012). Sino-Cuban relations in the 21st century. International Journal of Cuban Studies, 4(3), 291-307.

Leverett, F., \& Bingbing, W. (2017). The New Silk Road and China's evolving grand strategy. The China Journal, 77(1), 110-132.

Li, P. S. (2005). The Rise and Fall of Chinese Immigration to Canada: Newcomers from Hong Kong Special Administrative Region of China and Mainland China, 1980-2000. International Migration, 43(3), 9-34.

Marrero, D. (2016). El rol de los supermercados chinos en la integración social de la población china en Buenos Aires / The Role of Chinese Supermarkets in the Social Integration of the Chinese Population in Buenos Aires. INDEPENDENT STUDY PROJECT (ISP) COLLECTION.

Martín, S. (5 de septiembre de 2017). Crisis en Venezuela también destruye sueños de inmigrantes: chinos regresan al país del que huyeron. Pan Am Post. https://es.panampost.com/sabrina-martin/2017/09/05/migranteschinos-regresar/

Martínez, S. \& Dussel, E. (2016). La diáspora china en México. Asociaciones chinas en el Distrito Federal, Mexicali y Tapachula. Migración y desarrollo, 14(26), 111-143. http://www.scielo.org.mx/scielo.php?script=sci_ arttext\&pid=S1870-75992016000100111\&lng=es\&tlng=es

Mei, W. X. (2014). Linguagem, interação social e cultura: alternância de código chinês-português por imigrantes chineses no Rio Grande do Sul. Caixas Do Sul.

Mellander, G. (1999). Charles Edward Magoon, the Panama Years. Editorial Plaza Mayor Incorporated.

Mote, F. W., \& Twitchett, D. (1988). The Cambridge History of China. Cambridge University Press.

Moreno, C. (2015). O Brasil made in China: para pensar as reconfigurações do capitalismo contemporâneo. Fundação Rosa Luxemburg. 
Organización Internacional para las Migraciones (OIM). (2020). Informe sobre las migraciones en el mundo 2020. https://publications.iom.int/ books/informe-sobre-las-migraciones-en-el-mundo-2020

Paladini, S. (2011). A view from the Isthmus: China's strategic interests in Latin America between Taiwan and the USA. The Journal of Comparative Asian Development, 10(1), 62-89. http://dx.doi.org/10.1080/15339114 .2011 .578476

Paz, G. S. (2018). Remapping Latin America and East Asia Interregional Relations. Interregionalism and the Americas, 163. Rowman \& Littlefield. Portes, A. \& Armony, A. C. (2016). Rescatando valores ancestrales y creando nuevos lazos: el transnacionalismo chino en América Latina. Migración $y$ desarrollo, 14(26), 3-23.

Recabarren, M. A. (2014). Hijos del Dragón: inmigrantes chinos y su inserción socioeconómica en la provincia de Taparaca, 1860-1940". Revista de Ciencias Sociales (Cl), (32), 25-62.

Rodríguez, H. (2000). Herederos del dragón. Historia de la comunidad china en el Perú. Lima: Fondo Editorial del Congreso del Perú, 2000, 526 pp. Histórica, 25(2), 341-343.

Rodríguez, O. (2012). Chinese-Mexicans celebrate repatriation to Mexico. The San Diego Union Tribune.

Rosales, A. (2018). China and the decaying of socialist rentierism in Venezuela: instability and the prevalence of non-interventionism. Third World Thematics: A TWQ Journal, 3(4), 552-568. http://dx.doi.org/10.1080/23 802014.2018.1496797

Sánchez, G. (27 de septiembre de 2010). La comunidad china en el país se duplicó en los últimos 5 años. Diario Clarín. http://www.clarin.com/ sociedad/comunidad-china-duplico-ultimos-anos_0_Syfgy52TDQe.html

Tam, J. (2006). Huellas chinas en Panamá: 150 años de presencia. Único Impresores.

Tamagno, C., \& Velásquez, N. (2016). Dinámicas de las asociaciones chinas en Perú: hacia una caracterización y tipología. Migración y desarrollo, 14(26), 145-166. http://dx.doi.org/10.35533/myd2003

Valderrey, F. J., Montoya, M. A., \& Sánchez, A. (2019). Latin America: The East Wing of the New Silk Road. Competition and Regulation in Network Industries, 21(1). https://doi.org/10.1177/1783591719853537

Vázquez, J. A. D. (2006). El "desembarco" de China en América Latina. Economía y Desarrollo, 140(2), 89-116. 
Vidal, J. A. (2003). La inmigración española en Cuba durante la primera ocupación militar norteamericana (1899-1902): El control del mercado laboral. Migraciones y Exilios: Cuadernos de la Asociación para el estudio de los exilios y migraciones ibéricos contemporáneos, (4), 31-49.

Villalever, X. A., \& Rubio, F. (2019). New Patterns of Chinese Migration to the Americas: Mexico City and Lima. En New Migration Patterns in the Americas (pp. 261-281). Palgrave Macmillan, Cham.

Yankelevich, P. (2004) Extranjeros indeseables en México (1911-1940). Una aproximación cuantitativa a la aplicación del artículo 33 constitucional. Historia Mexicana, LIII(3), 693-744.

Yongnian, Z. (2010). China and International Relations: The Chinese View and the Contribution of Wang Gungwu (Vol. 15). Routledge.

Zottele, E. \& Qian, W. (2017). La Franja y la Ruta: Oportunidad para América Latina y búsqueda de un desarrollo sostenible. Orientando, (13). https:// orientando.uv.mx/index.php/orientando/article/view/2527 